\title{
Peculiarities of Electric Power Engineering Terms Formation
}

\author{
Ekaterina S. Tarasova
}

\section{Anna A. Kradetskaya}

National Research Tomsk Polytechnic University, Institute of Power Engineering

Email: May.Sky15@gmail.com

\section{Doi:10.5901/mjss.2015.v6n2s1p62}

\section{Abstract}

The paper describes main ways of terms formation in the field of power engineering as this field of study has great potential for future development (renewable energy sources). The aim of this research was to investigate structure and processes involved into the terms building. The prevailing amount of them is constituted by multicomponent terms and terminological phrases. Morphological formation is the most widespread way of terms building. Another important detail regarding complex engineering terms is an attribute cluster. The authors analyze the structure of terminological phrases as well as consider challenges of terms translation. Multicomponent terms are the major challenge of understanding and translation, since these are word combinations formed according to a certain pattern. English and Russian attributive groups differ in their vectors. The research is also focused on neologisms definition and characterization. Neologisms are commonly formed by such linguistic means as compounding, conversion and meaning change. Though neologisms denote specific objects and are very distinctive, the translation process is rather challenging.

Keywords: terms formation, translation, terminological phrase, neologisms, power engineering

\section{Introduction}

In the modern world of scientific and technical literature where translators are often challenged with innovative texts containing descriptions of novel technologies, new scientific findings, new intellectual insights, etc. that unavoidably contain new terms (or changed meanings of existing terms), they are expected to coin and propose corresponding new terms in the target language. This process of language innovation is governed by a multitude of socio-cultural factors that determine the role of language in a particular society or language community, the cognitive factors of accepting new terms, etc. It is well known that every technical text comprises subject-field-specific terminology (often from different domains). A term is an integrative part of a lexical system of any language. Terms are also distinguished from other word categories by their enormous informational connotation. However, regarding translation, the term is considered to be one of the main challenges due to its sophisticated structure and possible polysemy.

In this paper we will be studying terminology in the sphere of electric power engineering. Firstly, this sphere has great potential for future development (renewable energy sources). Secondly, the analysis of the materials has shown that translators face certain challenges in identifying and translating professional and highly specialized vocabulary. Moreover, the following term analysis will be useful both for translation as well as for linguistics because it reveals the main structures deployed for terms formation.

Thus, there the following objectives of our study:

- $\quad$ to study the literature covering the issue stated in this study:

- to analyze main methods of terms formation;

- to investigate the challenges rising while translating;

- to consider peculiarities of neologisms and their characteristics.

Linguistic analysis of the literature on theoretical issues of terminology indicates the presence of a large number of definitions of a term. However, the widespread use of the word "term" referring to different objects cannot provide a logical and uniform definition. Thus defining of a term still remains an urgent problem. Basing on the existing definitions, we understand the term as a word or phrase which is a special object performing a specific function in a particular field of knowledge, and is also used for precise naming of concepts or phenomena characterizing a specific field of science and technology.

Though the issue of terminology cannot be considered the new one and lot of linguists studied the issues related to 
terminology and terms formation: Reformatskiy (2010), Wiersema (2004), Kostas, Mantzari, (2006), Hyde Parker (2009), Gerding-Salas (2000), Klimzo (2006), Kvo (2008), Alekseeva (2004), Hann (1992), Sager (1997), we would like to make an attempt to provide a study of terms formation in the specific field of science, i.e. power engineering.

Over the years there were numerous attempts to classify the main mechanisms for the formation of new terms. Summarizing the results of these studies we can state that the basic ways of terms formation are the following: 1) semantic (a word or phrase of a general language is used as a term); 2) morphological (a new term is generated by means of compounding, affixation); 3) syntactic (the formation of terminological phrases); and 4) the borrowing of words and phrases from the common lexis, other terminological systems and other languages); 5) abbreviations.

Since the main requirement to the term is its uniqueness, this requirement is implemented in two possible ways as there are two types of terms: 1) general scientific and technical terms, 2) special (nomenclature) terms. General scientific and technical terms express the general concepts of science and technology. Terms exist not only in the language, but in certain terminology system. Terminology as the system of scientific terms is a subsystem within a general lexical system. According to A.A. Reformatskiy (2010), terminology is a system of scientific concepts corresponding to the appropriate verbal expression. If the in general language (not within the terminology) the word can be polysemantic, then within the framework of the certain terminology, it becomes monosemantic. This statement is very important in terms of further analysis which will reveal the nature of terms formation if power engineering.

Specific character of terms as a special category of lexical words is that they are created in the process of production and research and therefore operate only within the environment which contains corresponding scientific and industrial realities, i.e. macro-context. Therefore, in contrast to general words, which meaning becomes evident through the situation or linguistic context, the monosemy of the term is regulated by both extralinguistic macro-context and linguistic micro-context.

The term does not require a context, as a general word does since it 1) is a member of a specific terminology that substitutes the context; 2) may be used independently, for example, in lists, registers or orders, and 3) it should be monosemantic not in the general language but within the terminology where it is used.

The accuracy of a term must be seen as its ability to reflect as far as possible the features that are provided in the definition. A term should be concise because if it is too long it will be violating the principle of linguistic economy. Moreover, it can lead to omission which can cause incorrect translation and misunderstanding.

In scientific and technical terminology such linguistic phenomena as polysemy, synonymy, homonymy may result in misunderstandings and above that rather severe translation mistakes. Therefore, before creating a new term for the concept several factors should be taken into account: first of all, a profound linguistic study should prove that there is no existing term in the language for the concept and secondly, if there are several synonymous terms for the concept the term which fulfills the maximal number of requirements should be approved.

\section{Term Formation Methods}

New terms can be formed in a certain environment, e.g. in a research laboratory, in an industrial company, at a conference, etc. Usually, a term is formed within the subject field in which it will be used; it is conditioned by the personal features of the persons involved, by the stimulus causing the term emerging, and of course, by the phonological, morphosyntactical and lexical structures of the language in which the new concept finds its linguistic expression.

In the sphere of science and technology, particularly in electric and power engineering fields, multicomponent terms form more than $80 \%$ of the entire word stock. This tendency finds its reflection in numerous multicomponent terminological combinations, such as e.g. power-flow-type relay, capacitor-compensated transmission line, secondary grid-type distribution system etc.

Word borrowings from other languages are negligible in this point of consideration, since these lexical units do not exceed 3-4\%. Suffixation is the most common type of morphological word formation; $5-18 \%$ of terms are formed this way.

Current English scientific and technical literature is characterized by an increasing number of various contractions (abbreviations) among all morphological word classes and combinations as well as by formation of new words via contraction of the existing ones (today there are more than 250000 abbreviations registered in Romanized countries). This is a result of communication informational optimization and reveals a tendency to minimize complicated signs, e.g.:

- VAR - Volt-Ampere-reactive;

- RMS - root-mean-square;

- EMF - electro-motive force;

- STATCOM - Static Synchronous Compensator;

- SVC - Static VAR compensator; 
- TCR - Thyristor Controlled Reactor;

- $\quad$ TSR - Thyristor Switched Reactor;

- MSC - Mechanically Switched Capacitor

- ALNICO - Aluminum-Nickel-Cobalt alloy.

Attributive clusters as a main method of terms formation become more and more widespread in practice. This is reasoned by external factors. First of all, any language has a limited amount of lexical units. Secondly, the results of scientific and technical revolution have led to new discoveries and phenomena which require specific definitions and nominations.

Lexical-semantic way of terms formation creates a serious competition to such traditional methods as semantic and morphological; these combinations are the most used nowadays. Terminological phrases are semantically cohesive combinations of two and/or more words linked with a preposition (e.g. battery-to-high-voltage DC power supply - a storage device for a direct-current power supply of high voltage) or without it (e.g. air-gap-wound generator - a generator with windings in the air gap). Such combinations can be either a set expression or a free phrase. When using a certain terminological phrase it is necessary to understand the order of its translation.

The issue of terms translation is very urgent from the point of finding their equivalents in the target language and specifically the issue of multicomponent terms. Multicomponent terms present the major challenge of understanding and usage, since these are word combinations formed according to a certain pattern i.e. attributive clusters. English and Russian attributive groups differ in their vectors. The English phrase is regressive, that is, it develops to the left, with the headword being the final element on the right. The Russian attributive phrase is progressive, it develops mostly to the right, with the attributes used in postposition.

Conventional translation process involves the analysis of the terminology contained in the source text, comparison of the source language terminology to that of the target language, the target text production including the selection of appropriate terms according to the prospective communicative purpose(s) of the target text. However in order to translate a multi-structured attributive cluster, it is necessary to analyze the meaning of its constituents and then to adapt them to a proper Russian structure. Thus we will analyze the general and specific structures of the power engineering terms as the understanding of the inner mechanisms of terms formation will help to find the proper equivalent in the target language.

The main word in the non-prepositional terminological phrase is the last one, and all the words to the left of it play a secondary role - attributive, e.g.:

- step-down transformer - понижающий трансформатор,

- free-running generator - автономный генератор,

- gear motor - редукторный двигатель,

- $\quad$ wattage transformer - миниатюрный трансфрорматор.

Non-prepositional phrases can contain a large amount of information, e.g.:

- dry-type self-cooled transformer - сухой трансформатор с воздушным охлаждением,

- alternating-continuous current commutating machine - электромашинный преобразователь переменного тока в постоянный.

Terminological phrases are usually classified according to their lexical composition. There are terminological phrases consisting of:

- only nouns;

- adjectives and nouns;

- participles and nouns;

- adverbs, participles and nouns etc.

Let's consider the basic ways of their formation.

1. Terminological phrases consisting of nouns, e.g.:

- current rise,

- current transformer phase angle,

2. Terminological phrases consisting of adjectives and nouns, e.g.:

- $\quad$ high negative interference;

- short-circuit.

3. Terminological phrases consisting of participles and nouns, e.g.:

- padding capacitor;

- distributed amplifier.

4. Terminological phrases consisting of three components (adverb + participle (adjective) + noun), e.g.:

- separately-mounted circulating circuit component; 
- continuously-adjustable capacitor.

5. Terminological phrases consisting of three components (noun + adjective + noun), e.g.:

- voltage-sensitive device;

- net-dependable capability.

6. Terminological phrases consisting of three components (noun + participle + noun), e.g.:

- voltage-controlled capacitance;

- gas-filled rectifier.

7. Terminological phrases consisting of word groups where gerund is the main one, e.g.:

- full loading;

- brush sparking.

8. Terminological phrases with infinitive, e.g.:

- value to maintain relay closed;

- time to stable closed condition .

In terminological phrases consisting of a long attribute cluster, separate units can be linked to each other with a hyphen, e.g.:

- six-phase double-wye power rectifier circuit,

- double-acting diesel engine.

Terminological phrases are characterized by a main word standing before a preposition, and the words after it play an attributive role, e.g.:

- path of a winding;

- coat of varnish.

Terminological phrases can also have prepositional phrases as a part of them, which are the definition to the main word, e.g.:

- step-by-step regulator;

- front-of-panel mounting.

Terminological phrase allows to transfer information in a concise manner as well as to provide inter-phrase connection between sentences and paragraphs in technical documents.

\section{One-Word Terms in the English Language}

Suffixes and prefixes used in the English term formation are mostly borrowed from the general, ordinary word-building means of the English language. One of the peculiarities of terms formation is the attempt to reveal the meaning of some suffixes. This is especially evident for chemical and biological terms. In the terminology of other branches there is no such a systematic specialization of suffixes meaning. Thus the suffixes have a broader meaning referring to the category of the term concept.

Suffixes - er, - or, - ist form nouns denoting a skilled worker:

- operator;

- specialist.

as well as machines, tools and equipment:

- transformer;

- generator;

- capacitor.

Nouns with the specific meaning are formed by the suffixes- ing, - ment:

- heating;

- piping;

- development.

Abstract nouns are formed by means of suffixes that express the properties and qualities:

- ness (business);

- ty (safety);

- hood (likelyhood).

Suffix-ing is used to denote technological processes and actions as a whole:

- turning;

- programming rotating.

Suffix - (t) ion expresses actions: 
- transmission;

- distribution;

- generation.

Scientific and technical terminology is characterized by a number of suffixes and prefixes, low-productive, unproductive and absent in the general language. So, English term formation system widely uses the following unproductive suffixes:

- $\quad$ ment (treatment, filament);

- $\quad$ ance, - ence (inductance, divergence).

The terminology system widely uses adjective suffix - wise, giving the meaning "in a direction to, parallel with":

- streamwise;

- clockwise.

Some low-productive prefixes are widely applied in terms formation:

- non-corroding;

- non-dimensional;

- non-freezing.

Some suffixes and prefixes related to the terms formation are absent in the general English.

For example, English term building prefix as- is used with the past participle and means "directly in the state, which the subject has acquired undergoing the process expressed by the participle":

- as-cast (immediately after casting);

- as-controlled (immediately after controlling);

- as-welded (immediately after welding).

In many areas special rules were developed to form terms denoting concepts or objects of a particular class. Thus, the names of various types of electron tubes were created by analogy with the term electrode determining the number of electrodes used:

- diode;

- triode.

To sum up, we would like to note that one-word terms are heterogeneous in the number of word-building components. Thus, there are following groups of one-word terms:

I. One-root term:

- grid;

- shaft;

- supply.

II. Blending.

Root + one or several affixes:

- acknowledgment;

- distribution;

- wireless.

Terms formed by the blending of two roots:

- busbar;

- blackout;

- network.

Terms formed by the blending of word parts:

- Internet;

- modem;

- netiquette.

Terms formed by root blending and affixation:

- broadcasting;

- subnetwork.

Thus, summarizing all mentioned above it can be concluded that complexity and the multifaceted nature of term formation affect the translation process. Word-building patterns used for term formation refer to specific terminology and can be low-productive or even absent in the general language. 


\subsection{Neologisms: Characteristics and Challenges}

Language of science and technology is closely intertwined with the process of invention especially in such a rapidly developing sphere as electric power engineering. The focus of the scientific community towards new energy sources, i.e. renewables stipulated a wide range or research in this area. Consequently every newly discovered concept needed a term to be designated. However, not every term is considered to be a neologism.

In compliance with the ISO/TC37 [1087-1:2000], a neologism is defined as "new terms coined for a given concept", i.e. these are the terms regardless of being either simple or complex which were introduced into the language for the first time and, furthermore, they were generated by means of derivation, compounding or blending. Another conclusion that can be drawn from this definition is that borrowings from other languages should not be considered as neologisms.

Conventionally, all neologisms can be divided into two main groups: new words and new meanings of the words already existing in the language. Both groups are sufficiently challenging in terms of translation since their meanings cannot be found both in traditional English-Russian dictionaries and even in new English-English dictionaries. Every person involved in translation knows that dictionaries lag behind the process of words registration for approximately several years.

Another challenge which is interfering with neologism registration both in bilingual and monolingual dictionaries is the fact that neologisms exist in the language for a short period of time. In that aspect they can be compared to slang words. Neologisms as well as slang words tend to appear very quickly especially in social and political spheres, science, technology and I.R. Galperin (1977) stated that dictionaries cannot and moreover should not register them. Hence, many neologisms refer to "occasional" or nonce words. This occasional character is enhanced if a new word comes from the slang which is a highly dynamic part of the language. Neologisms are commonly formed by such linguistic means as compounding, conversion and meaning change.

Eventually it should be emphasized that adequacy in translation can be reached if the following conditions are observed:

- to know peculiarities of the context and main cases where neologism is used;

- to know main techniques and transformations as well as to have profound knowledge in the target language terminology in order to find equivalent variant which will match the neologism in the source language;

- to select and use the appropriate way of creating new equivalent in the target language for a term which concept does not exist in the reality of the target language.

Though neologisms denote specific concept and are very distinctive, the translation process is rather challenging.

\section{Conclusion}

The analysis of terms formation depends on the type of a term and is defined by the number of components, and this in its turn defines a terminological phrase. Terminological phrase allows to compress the information and to form interphrase ties between sentences and paragraphs in scientific and technical texts.

Formation analysis of English power engineering terms leads to the conclusion that the main ways of their formation are syntactic, semantic and morphological, they can be also built through the borrowings from other languages and special-field terminology. Most of the contemporary English terms have syntactical origin.

Described topic is seen as relevant because continuous development of power industry and constant search for new sources of energy reveal a potential for new terms formation and consequently for their translation. Though being monosemantic, terms can be also polysemantic in general language.

There are certain rules that can help to translate multicomponent terms and neologisms. In the process of translation, it should be noted that the shape and content of terms do not always coincide in target and source languages, i.e. the translator has to focus on these peculiarities in order to avoid mistakes that can lead to misunderstanding or even misinterpretation.

\section{References}

Alekseeva, I. S., (2004). Professional translator training. Moscow: Soyuz. Galperin I. R., (1977). Stylistics. Moscow: Higher School.

Gerding-Salas, C., (2000). Teaching Translation // Translation Journal. Volume 4, No. 3.

Hann, M. (1992). The Key to Technical Translation. Volume 1: Concept specification. John Benjamins Publishing Company, pp. 248 p. Hyde Parker, R., (2009). Professionalizing Literary Translation Education // Translation Journal. Univ. of East Anglia, UK. Volume 13, 
No. 2.

ISO 1087-1:2000, Terminology work - Vocabulary - Part 1: Theory and application.

Klimzo, B.N., (2006). The work of a technical translator. Moscow: Valent.

Kostas, V, Mantzari, E., (2006). The Linguistic Dimension of Terminology: Principles and Methods of Term Formation // Materials of 1st Athens International Conference on Translation and Interpretation Translation: Between Art and Social Science, pp: 1-20.

Kvo, Ch.K., (2008). Translation Technologies. Moscow: Akademia.

Reformatskiy A.A. (2010). Introduction to Liguistics. Moscow: Aspect Press.

Sager, J.C., (1997). Term formation. In: Handbook of terminology management. Sue Ellen Wright \& Gerhald Budin (eds.). Amsterdam: John Benjamins, pp. 25-41.

Wiersema, N., (2004). Globalisation and Translation. A discussion of the effect of globalisation on today's translation // Translation Journal: 1: 48-59. 